\title{
Reproductive Output and Insect Behavior in Hybrids and Apomicts from Limonium ovalifolium and L. binervosum Complexes (Plumbaginaceae) in an Open Cross-Pollination Experiment
}

\author{
Sofia I. R. Conceição ${ }^{1}\left(\mathbb{D}\right.$, Joana Fernandes ${ }^{1}$, Elsa Borges da Silva ${ }^{2} \mathbb{D}$ and Ana D. Caperta ${ }^{1, *}$ \\ 1 Linking Landscape, Environment, Agriculture and Food (LEAF), Instituto Superior de Agronomia (ISA), \\ Universidade de Lisboa, Tapada da Ajuda, 1349-017 Lisboa, Portugal; sofia-conceicao@hotmail.com (S.I.R.C.); \\ joanabnf@hotmail.com (J.F.) \\ 2 Forest Research Centre (CEF), Instituto Superior de Agronomia (ISA), Universidade de Lisboa, \\ Tapada da Ajuda, 1349-017 Lisboa, Portugal; elsasilva@isa.ulisboa.pt \\ * Correspondence: anadelaunay@isa.ulisboa.pt
}

check for

updates

Citation: Conceição, S.I.R.; Fernandes, J.; Borges da Silva, E.; Caperta, A.D. Reproductive Output and Insect Behavior in Hybrids and Apomicts from Limonium ovalifolium and L. binervosum Complexes (Plumbaginaceae) in an Open Cross-Pollination Experiment. Plants 2021, 10, 169. https://doi.org/ 10.3390/plants10010169

Received: 2 November 2020 Accepted: 11 January 2021 Published: 17 January 2021

Publisher's Note: MDPI stays neutral with regard to jurisdictional clai$\mathrm{ms}$ in published maps and institutional affiliations.

Copyright: $(\odot 2021$ by the authors. Licensee MDPI, Basel, Switzerland. This article is an open access article distributed under the terms and conditions of the Creative Commons Attribution (CC BY) license (https:// creativecommons.org/licenses/by/ $4.0 /)$.

\begin{abstract}
Ex situ plant collections established from seeds of natural populations are key tools for understanding mating systems of intricate taxonomic complexes, as in the Limonium Mill. genus (sea lavenders, Plumbaginaceae). Plants show a polymorphic sexual system associated to flower polymorphisms such as ancillary pollen and stigma and/or heterostyly that prevents self and intramorph mating. The main objectives of this study were to investigate the significance of pollenstigma dimorphisms and the role of flower visitors in the reproductive output of hybrids arising from sexual diploids of Limonium ovalifolium complex and apomicts tetraploids of L. binervosum complex in an open cross-pollination experiment. Results showed that, similarly to parental plants, hybrids present inflorescence types, self-incompatible flowers, and produced regular pollen grains with the typical exine patterns, with medium to high viability. By contrast, apomicts show floral polymorphisms, inflorescences, and pollen grains of maternal phenotype but with low stainability. Several insects' species visited the inflorescences of parental plants and both hybrids and apomicts and some of these insects carried A and/or B pollen grains on their bodies, especially Clepsis coriacana (Rebel) and Tapinoma sp. Insects' floral visits to hybrids and apomicts seem to be independent of pollen fertility and plants' reproductive modes. Both hybrids and apomicts were able to produce fertile seeds, although the latter showed more seedlings with developmental anomalies than the first plants. The findings demonstrate that there is a weak reproductive barrier between the diploid species of L. ovalifolium complex as they can hybridize and produce fertile hybrids, provided there is pollen transport by pollinator insects. This study supports that apomixis is a strong reproductive barrier between both L. ovalifolium and L. binervosum complexes but did not allow us to exclude reproductive interferences of apomict pollen into sexuals.
\end{abstract}

Keywords: ancillary pollen and stigma polymorphisms; apomixis; flower heteromorphism; pleiocotyly; polyembryony; polyploidy; reproduction

\section{Introduction}

In flowering plants hybridization and polyploidy are important evolutionary processes often connected to changes in the reproductive systems [1-4]. In the genus Limonium Mill. (sea lavenders Plumbaginaceae), plants characteristically show striking flower polymorphisms linked to a sporophytic self-incompatibility system, which is associated with distinct reproductive modes, sexual and/or apomixis (agamospermy, asexual reproduction through seeds) [1-8]. Most species show ancillary pollen (e.g., differences in pollen production, size, shape, and exine sculpturing) and stigma heteromorphisms (e.g., papillae size and morphology) generally linked with heterostyly (pistils' and stamens' sizes in 
alternate morphs) that prevents self and intramorph mating [1-3,5,7-9]. Some Limonium species are heterostylous (e.g., Limonium vulgare) [2,3,9-11], despite most of them being non-heterostylous but with pollen-stigma polymorphisms [2,7-9,12].

Dimorphic species usually show reciprocal heteromorphic incompatibility, in which flowers of one mating morph produce coarse reticulate sexine (A type pollen) and coblike stigmatic papillae, whereas the complimentary morph shows finely reticulate sexine (B type pollen) and papillate stigmas [1,5,6] (Figure 1a). Dimorphic species' populations have roughly equal numbers of self-sterile $\mathrm{A} / \mathrm{cob}$ and $\mathrm{B} /$ papillate plants and reproduce sexually through outcrossing, as is the case of Limonium ovalifolium (Poir.) O. Kuntze and Limonium nydeggeri Erben diploid species $(2 n=2 x=15,16,17$ chromosomes, most frequent 16) $[1,5,6]$. In this system, coarsely reticulate pollen grains germinate on papillose stigmas (papillate cells) and finely reticulate grains germinate on cob-like stigmas (polygonal cells), while the reverse combinations produce no successful fertilization $[1,5,6]$ (Figure 1a). Monomorphic self-compatible species present A/papillate (D, self-fertile) or B/cob combinations $(C$, self-fertile, more frequent). In contrast, monomorphic self-incompatible populations of species showing only one pollen-stigma combination (either A/cob or $\mathrm{B} /$ papillate) seem to produce seeds through apomixis as seen for Limonium binervosum (Sm.) C.E. Salmon and Limonium dodartii (Girard) Kuntze tetraploid species $(2 n=4 x=35$, 36 chromosomes, most frequent 36) [1-3,5-8] (Figure 1a).

The primary reproductive strategies of Limonium species have been inferred upon analyses of such flower heteromorphisms $[1,5,6,8]$. Generally, sexual species like those of L. ovalifolium complex present full anthers ( $>100$ pollen grains, $~ 53.52 \pm 5.6 \mu \mathrm{m})$ and pollen with high viability $(\sim 80-100 \%$; $[2,3,7,12])$. By contrast, apomicts of the L. binervosum complex show empty anthers or few pollen grains $(<100)$, with diverse morphology and sizes [7,12], with high to low fertility, since grains can be partly or totally aborted $[2,7,12,13]$. Thus, this polymorphic sexual system linked to floral traits (ancillary pollen and stigma polymorphisms) can be considered a prepollination reproductive barrier that separates the diploid and the tetraploid species' complexes. Both Limonium heterostylous sexual $[3,5,6,11,14]$ and apomictic [15] taxa seem to provide floral resources to insect visitors under field conditions. However, whether pollinators have different pollen transfer proficiencies in diploid and tetraploid plants with distinct reproductive modes is unknown.

Molecular genetic studies show evidence for hybrid origin of apomictic taxa (e.g., [4,16-20]) toward vegetative apomixis or agamospermy, as hypothesized for Limonium [2,13]. Sexual species like those of diploid Limonium ovalifolium complex (L. ovalifolium, L. nydeggeri, L. lanceolatum (Hoffmanns and Link) Franco) mostly form meiotically reduced tetrasporic embryo sacs of Gagea ova type and tetrasporous gametophytes of Adoxa and Drusa types [7,21]. Apomicts such as those of Limonium binervosum complex (i.e., L. binervosum, L. dodartii, L. multiflorum Erben) may form meiotically unreduced diplosporous and reduced embryo sacs (facultative apomixis) or unreduced diplosporous embryo sacs and autonomous endosperm (obligate apomicts) $[7,22,23]$. A previous study using some of those Limonium plants in homoploid (diploid $\times$ diploid) and heteroploid (tetraploid $\times$ diploid) experimental crosses revealed genetically diverse offspring arising from sexual reproduction, whereas maternal, clonal offspring was produced by apomixis [4] (Figure 1).

This study on plants produced in homoploid and heteroploid experimental crosses [4] through sexual or apomictic reproductive modes addressed the following specific questions: (1) Do floral combinations (ancillary pollen and stigma polymorphisms) of parental plants used in the crosses persist in their progeny? (2) Is there a pollinator preference for a flower type? (3) Are there differences between plants produced through different modes of reproduction in terms of reproductive outcomes? To address these questions, we analyzed Limonium diploid hybrids and tetraploid apomicts obtained after controlled hand pollinations comparing the reproductive outputs among plants. 
(a) Pollen-stigma combinations characteristic of the Limonium genus [2]. (a1) Limonium species used as parental generation [4]. (a2) Reproductive modes of the utilized species.
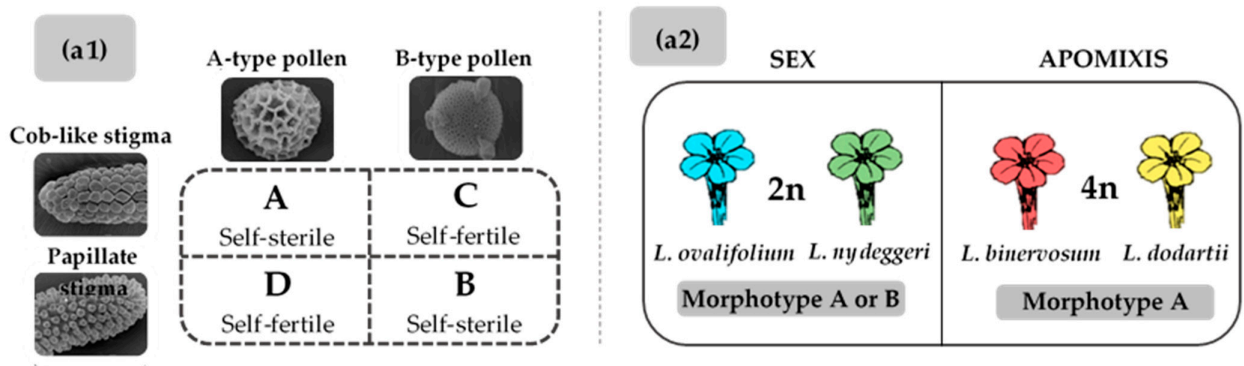

(b) Controlled pollination experiments using parental plants [4].

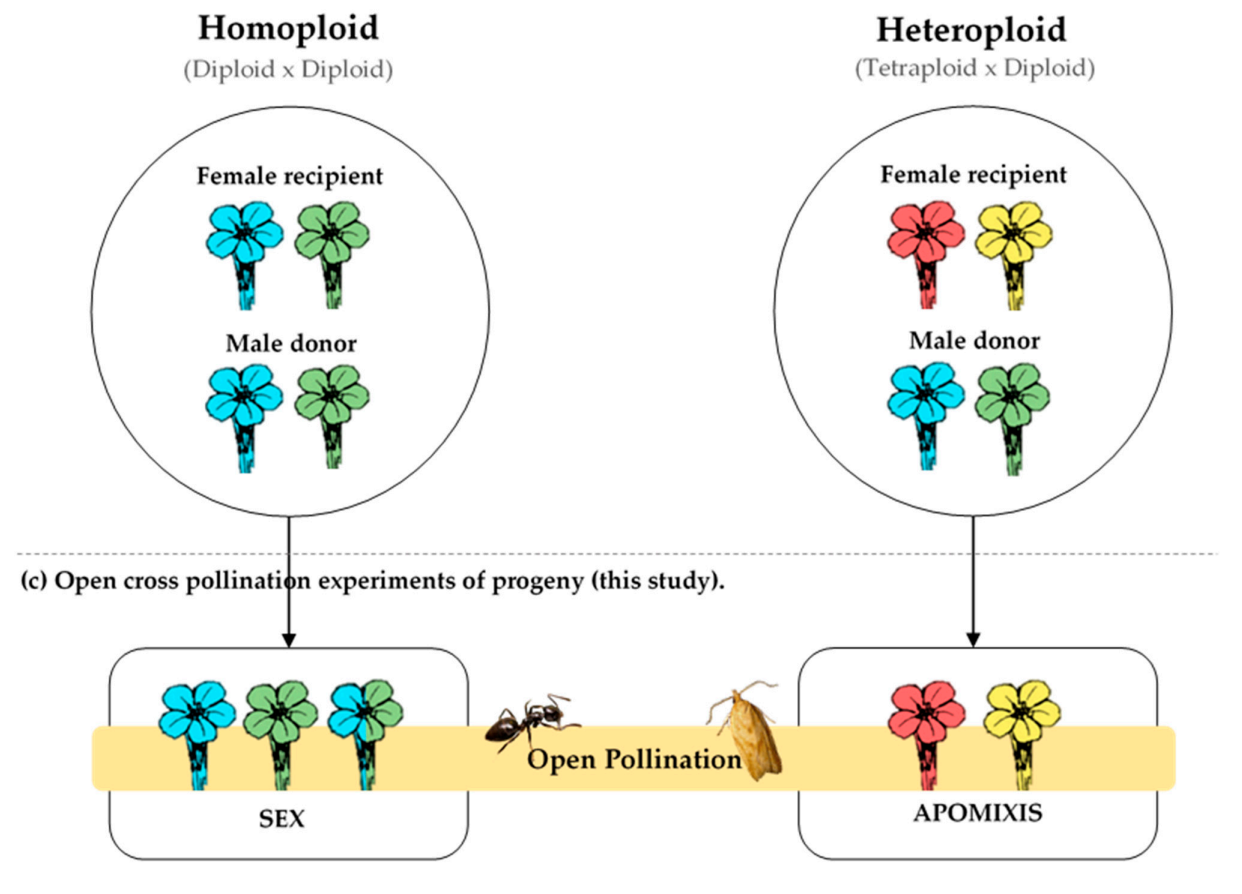

Figure 1. Workflow of the homoploid and heteroploid crosses performed in Limonium plants from a controlled ex situ crossing experiment, adapted from $[4,7]$. For schematic purposes and easy understanding of this figure, the meaning of the color code used for the flowers in section A is maintained throughout the remaining figure sections. In section (a), the pollen (A and B) and stigma types (cob-like and papillate) found in the Limonium genus [7] are represented and exemplified by L. binervosum, L. dodartii, L. nydeggeri, and L. ovalifolium. Pollen grains with macroreticulate exine germinate on papillose stigmas surfaces, whereas pollen grains with microreticulate exine germinate on cob-like stigmas [1]. Section (b) shows the parental species previously characterized in [7] and utilized in the controlled homoploid (diploid $\times$ diploid) and heteroploid (tetraploid $\times$ diploid) crosses realized in spring 2016 [4] as well as female recipients and male donors used in each cross. The resulting offspring plants were characterized in terms of morphology, ploidy levels, and reproductive modes as assessed by nuclear ribosomal DNA analyses in 2017-18 [4,7]. Section (c) represents the plants reproductively characterized in this study. These plants were subjected to open pollination and allowed to be visited by insects in 2019 within a semi-closed greenhouse.

\section{Results}

\subsection{Inflorescence Phenotype, Pollen-Stigma Combinations, and Pollen Viability}

In total, 36 plants originated in homoploid crosses and 15 plants produced from heteroploid crosses were analyzed (Figure 1, Table 1). There were significant differences between the two reproductive modes relatively to pollen-stigma combinations (Table 2). Plants originated from intraspecific crosses presented the pollen-stigma dimorphisms 
and inflorescence morphotypes like both parental plants. Hybrid plants produced in interspecific homoploid crosses using L. nydeggeri and L. ovalifolium showed either A or B self-incompatible combinations (cross two: five plants with combination $B$ and four plants with combination $A$; cross three: all plants with combination $A$; cross five: four plants with combination B and three plants with combination A). Contrastingly, apomicts had always the same self-incompatible pollen-stigma combination of the maternal type (A), except for one plant that showed a self-compatible combination (C) (Table 1). No individuals with self-compatible combination D (microreticulate pollen/cob-like stigma) were found.

Table 1. Pollen-stigma combinations and inflorescence phenotypes of investigated plants. These plants were produced in homoploid (diploid $\times$ diploid) and heteroploid (tetraploid $\times$ diploid) experimental crosses carried out in [4]. * Pollen-stigma combinations followed [7]: A: coarsely reticulate exine (A pollen)/cob-like stigma; B: finely reticulate exine (B pollen)/papillate stigma; and C: coarsely reticulate exine (A pollen)/papillate stigma. A and B represent self-incompatible combinations (self-sterile) and $\mathrm{C}$ is a self-compatible (self-fertile) combination. No individuals with the self-compatible combination D (microreticulate pollen/cob-like stigma) were reported. The intermediate inflorescence morphotype combines characteristics of scapes from both Limonium ovalifolium and L. nydeggeri. Symbols: + — female recipient; $o^{\prime}-$ male donor.

\begin{tabular}{|c|c|c|c|c|c|c|c|c|c|c|}
\hline \multirow[t]{2}{*}{ Crosses } & \multirow[t]{2}{*}{ Parental Plants } & \multicolumn{3}{|c|}{$\begin{array}{l}\text { Pollen-Stigma } \\
\text { Combinations * }\end{array}$} & \multicolumn{5}{|c|}{ Inflorescence Morphotypes } & \multirow[t]{2}{*}{ Total } \\
\hline & & A & B & $\mathrm{C}$ & L. nydeggeri & Intermediate & L. ovalifolium & L. binervosum & L. dodartii & \\
\hline Homoploid & $\begin{array}{l}\mathrm{A}+\times \mathrm{Bo}^{7} / \\
\mathrm{B}+\times \mathrm{Ao}^{7}\end{array}$ & 19 & 20 & 0 & 8 & 9 & 18 & 1 & 0 & 36 \\
\hline Heteroploid & $\mathrm{A}+\times \mathrm{BO}^{\top}$ & 14 & 0 & 1 & 0 & 0 & 0 & 14 & 1 & 15 \\
\hline
\end{tabular}

Table 2. The probability and the likelihood ratio test (LRT) and respective $p$-value for the traits studied.

\begin{tabular}{cccc}
\hline Trait & Type of Reproduction & Probability & LRT Statistic Value $(p$-Value $)$ \\
\hline \multirow{2}{*}{ Colpi number } & Sexual & 0.99 & $580.85\left(<2.2 \times 10^{-16}\right)$ \\
\cline { 2 - 3 } Cotyledons number & Apomixis & 0.34 & $45.57\left(1.477 \times 10^{-11}\right)$ \\
\cline { 2 - 3 } & Sexual & 0.97 & 0.81 \\
\cline { 2 - 3 } Pollen-stigma combination & Apomixis & 0.59 & $16.61\left(4.59 \times 10^{-5}\right)$ \\
\cline { 2 - 3 } & Sexual & 1.00 & \\
\hline
\end{tabular}

These hybrids presented inflorescence morphotypes found in one of the parental plants or of intermediate type, between L. nydeggeri and L. ovalifolium (Table 1). The plants with intermediate inflorescence (from crosses three and five) showed pollen-stigma combination A or B. Two of the hybrid plants had an inflorescence morphology resembling that of L. binervosum (scape: slightly zigzagging, branching dichotomously in the upper third). Plants produced in heteroploid crosses only showed the maternal inflorescence types like apomict tetraploids L. binervosum or L. dodartii.

The hybrids produced variable numbers of pollen grains per anther with regular roundish morphology and the typical exine patterns, with medium to high fertility (Supplementary Materials Figure S1), mainly with three colpi (Table 3) like parental plants [4]. However, in one of the interspecific crosses plants formed pollen grains with atypical colpi number, most of them inviable (Table 3). There were significant differences between the two reproductive modes in relation to pollen colpi number (Table 2). The apomicts produced roundish pollen grains with the characteristic exine patterns, but with a variable number of colpi (from one to five) (Table 3). Although most grains showed regular form and aperture numbers (three colpi), these grains presented low pollen fertility (Table 3). 


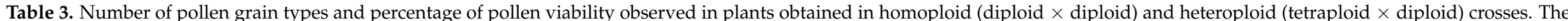

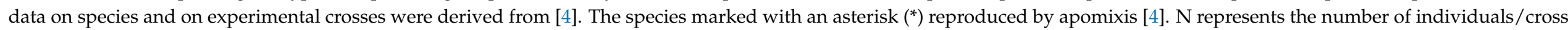
analyzed. Symbols: $\$$-female recipient; $\sigma^{x}$-male donor.

\begin{tabular}{|c|c|c|c|c|c|c|c|c|c|c|c|c|c|}
\hline \multirow{2}{*}{$\mathbf{N}$} & \multirow{2}{*}{$\begin{array}{c}\text { Cross } \\
\text { (\#) } q \times 0^{7}\end{array}$} & \multicolumn{5}{|c|}{ Viable Pollen with \#colpi } & \multicolumn{5}{|c|}{ Inviable Pollen with \#colpi } & \multirow{2}{*}{$\begin{array}{c}\begin{array}{c}\text { Pollen } \\
\text { Fertility }\end{array} \\
(\%)\end{array}$} & \multirow[t]{2}{*}{$N$} \\
\hline & & 1 & 2 & 3 & 4 & 5 & 1 & 2 & 3 & 4 & 5 & & \\
\hline \multirow{5}{*}{ Homoploid } & (1) L. ovalifolium $\times$ L. ovalifolium & 0 & 0 & 2507 & 0 & 0 & 1 & 0 & 349 & 2 & 0 & 87.7 & 6 \\
\hline & (2) L. nydeggeri $\times$ L. ovalifolium & 0 & 0 & 2709 & 0 & 0 & 0 & 2 & 480 & 0 & 0 & 84.9 & 8 \\
\hline & (3) L. nydeggeri $\times$ L. ovalifolium & 0 & 0 & 548 & 17 & 0 & 0 & 5 & 123 & 35 & 12 & 76.4 & 3 \\
\hline & (4) L. ovalifolium $\times$ L. ovalifolium & 0 & 0 & 2386 & 0 & 0 & 0 & 1 & 556 & 0 & 0 & 81.1 & 7 \\
\hline & (5) L. nydeggeri $\times$ L. ovalifolium & 1 & 1 & 2547 & 2 & 36 & 18 & 13 & 213 & 85 & 193 & 83.2 & 7 \\
\hline \multirow{3}{*}{ Heteroploid } & (11) L. binervosum * $\times$ L. nydeggeri & 0 & 0 & 0 & 0 & 0 & 8 & 31 & 317 & 91 & 0 & 0 & 6 \\
\hline & (12) L. binervosum * $\times$ L. nydeggeri & 0 & 0 & 14 & 20 & 21 & 32 & 63 & 1593 & 442 & 53 & 2.5 & 4 \\
\hline & (13) L. dodartii $*$ L. nydeggeri & 0 & 0 & 0 & 0 & 1 & 6 & 23 & 300 & 115 & 9 & 0.2 & 1 \\
\hline
\end{tabular}




\subsection{Floral Visitors}

In a total of $20 \mathrm{~h}$ of observation, 39 specimens of insects visited the inflorescences of parental plants, with no behavioral distinction of preference for either hybrid or apomict plants. The observed insects were from the orders Lepidoptera (55.9\%), Diptera (5.9\%), Hymenoptera (33.8\%), Coleoptera $(2.9 \%)$, and Heteroptera (1.5\%) (Figure 2). Most floral visitors from Hymenoptera were ants of Tapinoma sp. (Hymenoptera, Formicidae). Clepsis coriacana (Rebel) (Lepidoptera, Tortricidae) was the only Lepidoptera species found in inflorescences and leaves from all plant species (Figure 3). In addition to the behavioral evidence of insects' visits to the inflorescences, various specimens held pollen grains on their bodies (Figure 4), especially C. coriacana (18\% with pollen) and Tapinoma sp. ( $9 \%$ with pollen). Pollen grains of different sources were identified on the insects' bodies, including ones Limonium A and/or B type pollen (Figure 4). Further, C. coriacana individuals in all developmental stages (egg, larvae, pupae, adult) were found on plant structures (Figure 3), including a high level of $C$. coriacana exuviae in stored seeds.

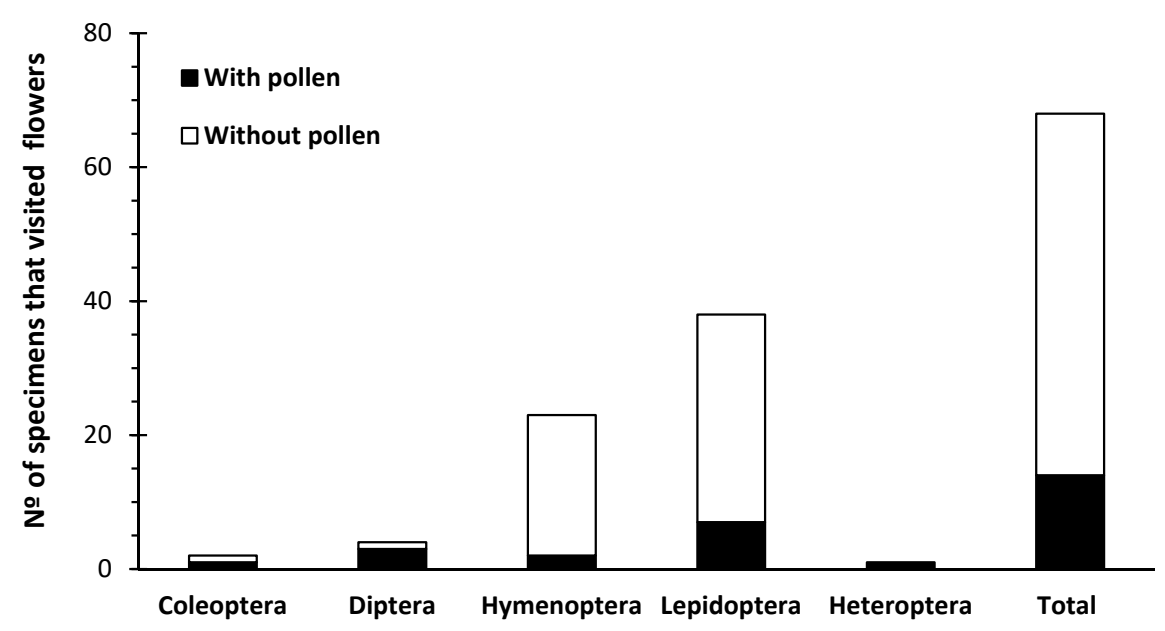

Figure 2. Representativeness of the insects (orders) carrying pollen or not that visited Limonium inflorescences.

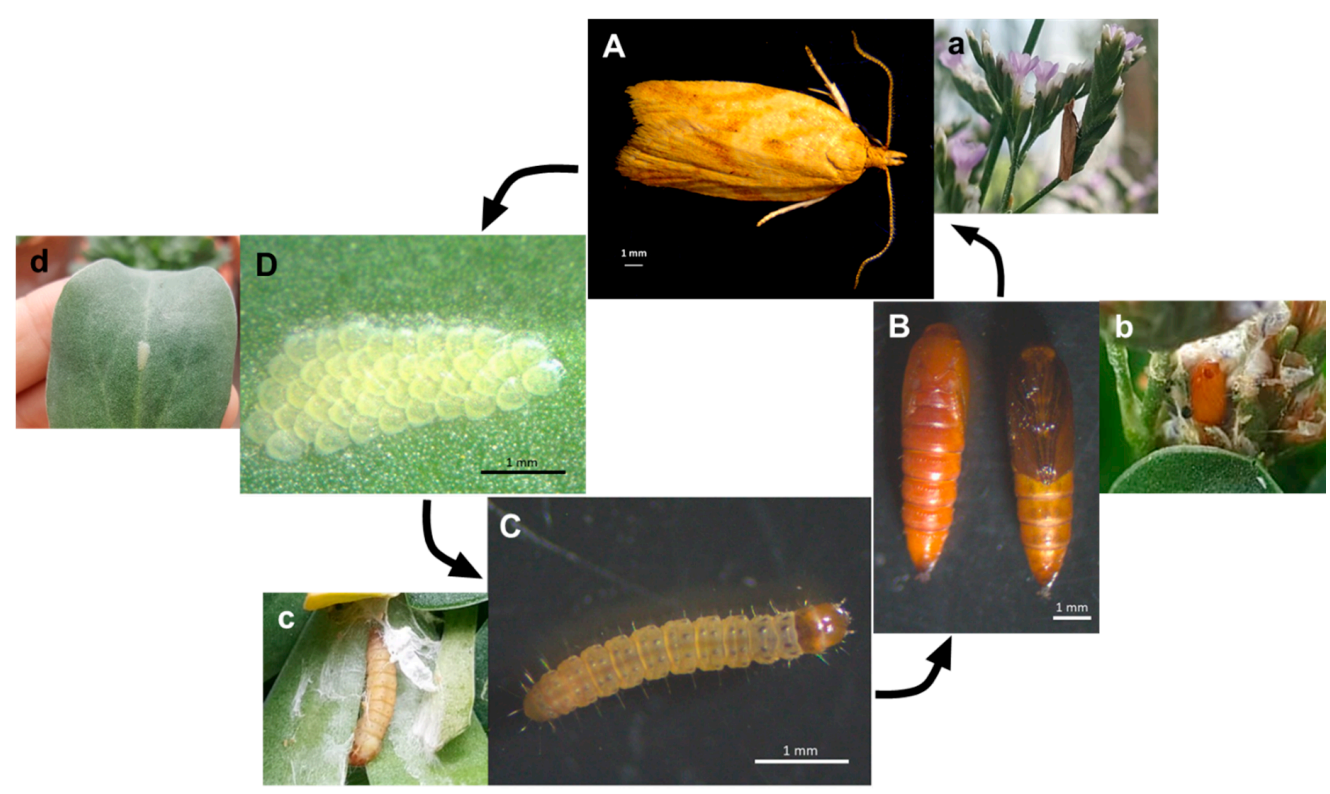

Figure 3. Life cycle of Clepsis coriacana (Rebel) (Lepidoptera: Tortricidae) in Limonium inflorescences and leaves. (A) Male and female adults (a); (B) pupae and detail of a pupae (b); (C) larvae and larvae on leaves (c); (D) eggs' cluster and eggs' cluster on a leaf $(\mathbf{d})$. 

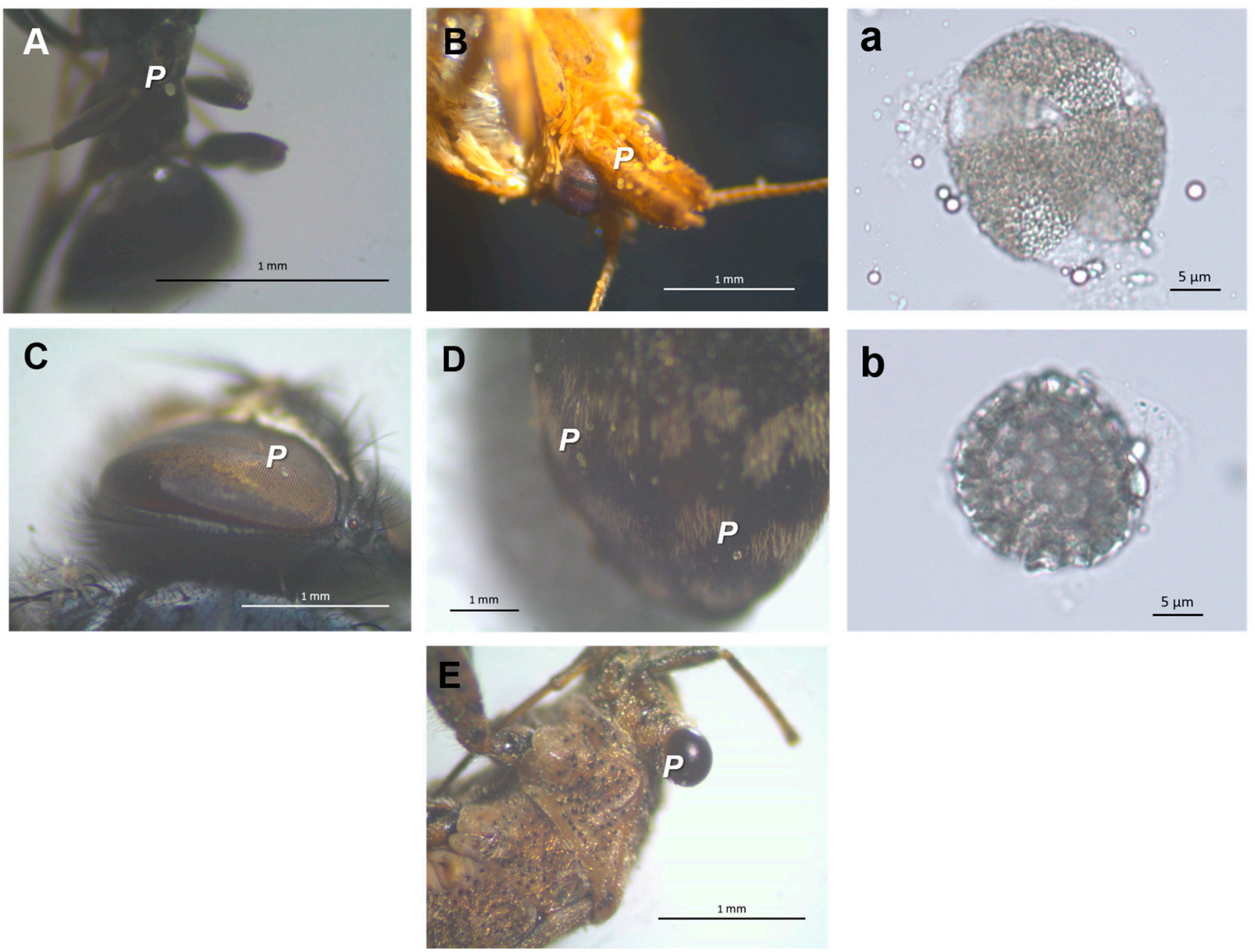

Figure 4. Pollen grains in insect pollinators from the five different orders observed during this study (A-E). Some of the pollen grains present on each insect captured are circled in red. (A) Tapinoma sp. (70×); (B) Clepsis coriacana $(40 \times)$; (C) Diptera $(45 \times)$; (D) Coleoptera $(45 \times)$; (E) Heteroptera $(45 \times)$; (a) Limonium pollen grain from A (a, colpi arrowed) or (B) (b) types.

\subsection{Seed Germination, Seedling Morphotype, and Ploidy Analyses}

Plants originated from different reproductive modes presented significant differences in relation to seedling morphotype (Table 2). The hybrids produced variable numbers of seeds per inflorescence, and a few plants of some crosses that showed inflorescences did not produced seeds (e.g., in cross 1 only one plant produced seeds) (Table 4). Plants that did not produce seeds were from both intra- and interspecific crosses and had either combination type A or B. The number of seeds produced by the hybrids was smaller than the tetraploid apomicts (Table 4). Conversely, all plants from the interploid crosses produced seeds. In both plant groups, the seed germination rates oscillated from medium to high values (Table 4). Most seedlings presented two cotyledons, although seedlings that originated from apomictic seeds showed a higher percentage of anomalies such as pleiocotyly (one, two, three, or four cotyledons) and polyembryony (i.e., the formation of more than one embryo per ovule) than those originated from hybrids' seeds (Table 5). Seedlings with more than two cotyledons or polyembryony derived from hybrid $(n=17)$ or apomictic $(n=255)$ plants revealed no differences in ploidy in relation to parental plants (Figure S2). 
Table 4. Number of seeds and rates of seed germination from open cross-pollination experiment of plants originated in homoploid (diploid $\times$ diploid) and heteroploid (tetraploid $\times$ diploid) crosses. The data on species and on experimental crosses were derived from [4]. The species marked with an asterisk ${ }^{*}$ ) reproduce by apomixis [4]. The number given in parentheses (\#) represents the number of germinated seeds. Symbols: $—$ female recipient; $\sigma^{\top} —$ male donor.

\begin{tabular}{|c|c|c|c|}
\hline & $\begin{array}{l}\text { Cross } \\
\text { (\#) } \propto \times 0^{x}\end{array}$ & Number of Seeds & $\%$ Seed Germination (\#) \\
\hline \multirow{5}{*}{ Homoploid } & (1) L. ovalifolium $\times$ L. ovalifolium & 1 & $100(1)$ \\
\hline & (2) L. nydeggeri $\times$ L. ovalifolium & 129 & $62(80)$ \\
\hline & (3) L. nydeggeri $\times$ L. ovalifolium & 149 & $90(134)$ \\
\hline & (4) L. ovalifolium $\times$ L. ovalifolium & 84 & $81(68)$ \\
\hline & (5) L. nydeggeri $\times$ L. ovalifolium & 107 & $84(90)$ \\
\hline \multirow{4}{*}{ Heteroploid } & (8) L. binervosum $*$ L. nydeggeri & 257 & $82(210)$ \\
\hline & (11) L. binervosum ${ }^{*} \times$ L. nydeggeri & 320 & $33(106)$ \\
\hline & (12) L. binervosum $*$ L. nydeggeri & 170 & $65(110)$ \\
\hline & (13) L. dodartii * $\times$ L. nydeggeri & 100 & $94(94)$ \\
\hline
\end{tabular}

Table 5. Percent of seedlings with certain morphotypes and polyembryony from open cross-pollination experiment of plants originated in homoploid (diploid $\times$ diploid) and heteroploid (tetraploid $\times$ diploid) crosses. The data on species and on experimental crosses were derived from [4]. The species marked with an asterisk $\left(^{*}\right)$ reproduce by apomixis [4]. The number given in parentheses represents the number of seedlings. Symbols: $q$-female recipient; $\sigma^{\top} —$ male donor.

\begin{tabular}{|c|c|c|c|c|c|c|}
\hline & \multirow{2}{*}{$\begin{array}{l}\text { Cross } \\
\text { (\#) }+\times \sigma^{7}\end{array}$} & \multicolumn{4}{|c|}{$\begin{array}{c}\text { Seedling Morphotypes } \\
\text { \#Cotyledons }\end{array}$} & \multirow[t]{2}{*}{ Poly-Embryony } \\
\hline & & 1 & 2 & 3 & 4 & \\
\hline \multirow{5}{*}{ Homoploid } & (1) L. ovalifolium $\times$ L. ovalifolium & 0 & $100(1)$ & 0 & 0 & 0 \\
\hline & (2) L. nydeggeri $\times$ L. ovalifolium & 0 & $100(80)$ & 0 & 0 & 0 \\
\hline & (3) $L$. nydeggeri $\times$ L. ovalifolium & 0 & $90(120)$ & $6(8)$ & 0 & $4(6)$ \\
\hline & (4) L. ovalifolium $\times$ L. ovalifolium & 0 & $97(66)$ & $3(2)$ & 0 & 0 \\
\hline & (5) L. nydeggeri $\times$ L. ovalifolium & $1(1)$ & $99(89)$ & 0 & 0 & 0 \\
\hline \multirow{4}{*}{ Heteroploid } & (8) L. binervosum * $\times$ L. nydeggeri & 0 & $83(172)$ & $5(10)$ & 0 & $12(26)$ \\
\hline & (11) L. binervosum $* \times$ L. nydeggeri & 0 & $67(71)$ & $3(3)$ & $2(2)$ & $28(30)$ \\
\hline & (12) L. binervosum $*$ L. nydeggeri & 0 & $77(85)$ & $3(3)$ & $4(4)$ & $16(18)$ \\
\hline & (13) L. dodartii * $\times$ L. nydeggeri & 0 & $97(91)$ & $1(1)$ & 0 & $2(2)$ \\
\hline
\end{tabular}

\section{Discussion}

The effects of hybridization, polyploidy (eu-, aneuploidy), and apomixis appear to have all contributed to shape the radiation of the genus Limonium [1,2,4,7,24-29]. Our investigation on plants obtained after controlled hand pollination crosses, using four species of Limonium from different species complexes, represents an attempt to evaluate the influence of the Limonium polymorphic sexual system and insect behavior in their reproductive outcomes inferred from an open-pollination experiment. Our analyses revealed several novel findings. (1) Crosses between diploid species produced fertile and infertile hybrids with both the maternal and paternal pollen-stigma combinations and inflorescence types, and some of them presented intermediate inflorescence morphotypes. (2) Crosses between diploids and tetraploids originated fertile plants with the maternal morphotype only but with high levels of inviable pollen. (3) Pollen transport (A and/or B) by distinct insect visitors was observed in all plants, independently of pollen fertility and plants' reproductive modes, sexual or apomixis. The findings support that apomixis is a reproductive barrier between the diploid and the tetraploid species. Nonetheless, since we carried out an open-pollination experiment, and there are species in the L. binervosum complex that seem to be facultative apomicts [23], rare hybridization events through reproductive interference mediated through cross-fertilization of sexuals by apomicts could occur. 
A previous study using pollen-stigma polymorphic Limonium plants as progenitors revealed diverse diploid hybrids arising from sexual reproduction in homoploid crosses and tetraploid plants with the maternal phenotype produced by apomixis in heteroploid crosses [4]. Here, we found that diploid hybrids globally have similar inflorescence types and self-incompatible combinations (i.e., pollen A/cob-like stigma or pollen B/papillate stigma) like parental plants [4]. Two of the hybrids presented inflorescence morphologies like L. binervosum and were tetraploid. These unexpected phenotypes could hypothetically be due to reproductive interferences mediated by cross-pollination between plants since apomicts produced both viable and inviable pollen grains. Asymmetric reproductive interference in favor of apomicts was found in the case of cross-fertilization by cytotypes of differing ploidy, involving sexuals and apomicts in Potentilla puberula (Rosaceae) [30]. In mixed populations in the field, apparently, reproductive interferences of $P$. puberula sexuals by apomicts appear to be negligible [31]. In the case of the species studied here, mixedploidy populations of sexual diploids of L. ovalifolium complex and apomicts tetraploids of L. binervosum complex rarely occur [12,24]. Morphological, cytogenetic, and genetic studies using cpDNA (Chloroplast DNA) markers and MSAP (Methylation Sensitive Amplified Polymorphism) markers demonstrated a differentiation between diploid and tetraploid taxa of the studied sexual and asexual complexes $[7,25,29]$. Although cpDNA analyses revealed species-specific lineages, suprahaplotypes (closely related haplotypes) were found to be shared among taxa. Even if there is transference of pollen from apomicts to sexuals in the open-pollination experiment here studied, it is not known whether this phenomenon occurs in the field.

In apomicts the inflorescences and pollen-stigma combination are of maternal type (i.e., A/cob-like stigma), with exception of one plant that was self-compatible (i.e., pollen $\mathrm{A} /$ papillate stigma). It could be hypothesized that this latter finding could result from the breakdown of the self-incompatibility system brought about by cross-pollination. Alternatively, this result could be interpreted as the result of a (rare) hybridization event. For example, in the apomictic Ranunculus auricomus (Ranunculaceae) polyploid complex both diploid sexual taxa and their $F_{1}$ hybrids are completely self-incompatible, but breakdown of self-incompatibility was observed in the rather widespread allohexaploid apomicts (a phenomenon known as mentor effects) [32]. Mentor effects were also found in diploid Hieracium alpinum (Compositae) under the influence of foreign pollen from another species of this genus during a series of crossing experiments and after cross-fertilization of sexuals and apomicts of $P$. puberulla $[30,33]$.

The diploid hybrids display medium to high pollen viability similarly to their parental plants (Figure S1). Both diploid hybrids and tetraploid apomicts produce pollen grains with either more or less than three colpi, although the most frequent pollen grain type in both plant groups present three colpi and are viable. At least in some of the crosses, the low level of pollen fertility found in the apomictic progeny contrasts with that of their apomictic mother plants that show high pollen fertility (Figure S1). This unexpected result could be explained that during the flowering period the pollen viability of some of the apomicts decreased gradually and more rapidly than in sexual hybrids, i.e., the pollen had low longevity. At least one species of the L. binervosum complex ( $L$. transwalianum) is a facultative apomict [23]. In this case, the pollen of this species may be functional at least for endosperm formation and/or eventually it could be transferred to sexuals in sympatric populations. Another apomict tetraploid from this complex is L. multiflorum that forms irregular, abnormal microspores with a collapsed morphology without the typical exine patterns, which are inviable [12]. All the plants from the apomictically established progeny form heterogeneous pollen probably related with residual male fertility due to meiotic disturbance caused by nonreduction via meiotic restitution as found in other Limonium apomicts (e.g., triploid L. algarvense Erben) [34].

Pollen viability levels seem to be important to determine flower visitation in some plant families like the Melastomataceae, since apomictic plants with no viable pollen or with pollen with low viability are not visited by pollinators [35]. Here, pollinators 
belonging to Lepidoptera, Hymenoptera, Diptera, Coleoptera, and Heteroptera orders visited flowering plants and carried A or B pollen on their bodies, irrespective of plants' pollen viability and reproductive modes (i.e., sexual or apomixis). Field studies reveal that Limonium flowers provide floral resources (pollen and nectar) to a diverse range and number of insects from different orders, including Diptera, Hemiptera, Heteroptera, Hymenoptera, and Lepidoptera (e.g., $[15,35,36])$. The greatest number of specimens visiting inflorescences and carrying Limonium-type pollen $[9,10,37,38]$ on their bodies are from the species C. coriacana ( $18 \%$ with pollen) and Tapinoma sp. ( $9 \%$ with pollen). Further, a high level of $C$. coriacana pupae and exuviae was detected in both Limonium stored seeds from experimental collections (this study) and natural populations (Sofia I. R. Conceição and A. D. Caperta, unpublished study). Limonium barceloi seeds from field plants are predated by insect (moth) larvae but the identity of this moth was not yet reported [15]. In fact, all stages of Clepsis coriacana (egg, larvae, pupae, adult) development are present in association with various organs of Limonium plants and use these plants as a food source (larvae feed on leaves and adults feed on pollen) and as a habitat (eggs are placed on leaves and larvae use leaves and flowers to pupate). Although C. coriacana being probably an exotic species, which was recently reported in Portugal [39] and for the first time in Europe (Gibraltar, in 2006) [40], the fact that it completes its life cycle in Limonium plants is strong evidence that this phytophagous insect lives associated with these plant hosts and actively participates in their pollination. Since C. coriacana has never been observed in association with other plants outside the greenhouse, it was likely transported along with specimens or parts of Limonium (i.e., leaves, inflorescences, seeds) from the field (e.g., south of Portugal and Morocco) and found favorable conditions for its establishment (i.e., climatic, plant hosts) in the greenhouses of Instituto Superior de Agronomia, Lisbon, Portugal. The prevalence of Limonium flowers' visits by C. coriacana supports its high dependence of these host plants for completing its life cycle, sustaining that this moth is an effective pollinator of Limonium plants.

In open cross-pollination experiment carried out in this study, it was found that the fertility of the diploid hybrids is variable, and not all plants produced seeds. Plants that did not produce seeds were from both intra- and interspecific crosses and had either combination type A or B. It could be hypothesized that in this latter case insect visits probably were not effective in pollination with the reciprocal pollen morph, as all hybrid plants were selfincompatible. However, the hybrids that show fertile inflorescences produced seeds with medium to high seed germination rates. Since these hybrids and parental plants are closely genetically related [4], severe meiotic disturbance leading to male and/or female infertility is not expected. Therefore, the reproductive barriers between these species/plants seem to be weak or inexistent. This might explain the finding that the diploid hybrid plants exhibit very few seed developmental anomalies like pleicotyly (more than two cotyledons) and polyembryony (i.e., the formation of more than one embryo per ovule) [41,42]. By contrast, all the apomicts produced seeds, even with low levels of pollen fertility, that apparently did not block endosperm formation. The progeny resulting of the apomictic seed development of maternal plants show various developmental seed anomalies, eventually produced by asynchronous and ectopic expression of several developmental pathways due to the presence of multiple genomes in polyploid plants [42]. Nonetheless, whether the tetraploid apomicts arise from autopolyploidy or allopolyploidy and which genomes are involved in their genesis has not yet been investigated, as far as we know. Finally, plants from each apomict progeny form fertile seeds that originate anomalous seedling (pleiocotyls, polyembryonic seedlings).

In conclusion, this study demonstrates that there are weak reproductive barriers between two of the species of the L. ovalifolium complex, since in interspecific crosses fertile hybrids were formed, at least in experimental, controlled crosses. Pollen vectors like insects appear to be important in cross-pollination of such species, as some of the self-incompatible hybrids did not produce seeds. Contrastingly, apomixis is a reproductive barrier between the diploid and tetraploid plants representing different complexes, since heteroploid crosses 
(apomictic tetraploid $\times$ sexual diploid) failed to produce true hybrids and the progeny arose via apomixis. Unfortunately, we were unable to make the reciprocal cross (sexual diploid $\times$ apomictic tetraploid) with the same pair of individuals that hypothetically could result in true hybrid progeny through male gametophyte from (pollen) apomicts. At least, tetraploid Limonium transwallianum belonging to the L. binervosum complex is a facultative apomict species [23]. Thus, we cannot exclude that, in the case of sympatry of diploid and tetraploid species, rare hybridization events via reproductive interferences of apomicts in sexual plants may occur.

\section{Materials and Methods}

\subsection{Plant Material and Growth Conditions}

The plants investigated in this study were originated in a controlled pollination ex situ experiment carried out in spring 2016 in the greenhouses of Instituto Superior de Agronomia (ISA), University of Lisbon, Portugal (Figure 1). Parental plants were established from seeds collected from natural populations. A total of 20 plants representative of diploid species L. ovalifolium and L. nydeggeri $(2 n=2 x=16$ chromosomes) and tetraploid species L. binervosum and L. dodartii $(2 n=4 x=35,36$ chromosomes) [7,12], respectively, were used in controlled homoploid and interploid crosses [4] (Figure 1a). Six diploid L. ovalifolium and L. nydeggeri self-incompatible plants with combination A or B (Figure 1a,b) were utilized in both intra- and interspecific homoploid (diploid $\times$ diploid) reciprocal crosses. In heteroploid crosses (tetraploid $\times$ diploid) five L. binervosum and three L. dodartii tetraploid plants with combination A were used. Reciprocal crosses using tetraploid plants were not possible to conduct, as until now we were unable to find mother plants with combination $B$ in the field. No flower emasculation prior to anther dehiscence was performed in inflorescences as the plants were self-incompatible [4,7]. The resulting plants from homoploid and heteroploid crosses, respectively, hybrids and apomicts (Figure 1c), were assessed using morphological reproductive and flow cytometry methodologies, and progeny analyses were made using nuclear ribosomal DNA sequences $[4,7]$.

The present reproductive study is based on the hybrids $(n=36)$ and apomicts $(n=15)$ obtained in the above-explained homoploid and interploid crosses [4]. Plants were cultivated within a semi-closed greenhouse at ISA/UL and grown in pots (5-cm diameter) using a commercial substrate (Siro, SIRO, Mira, Portugal).

\subsection{Inflorescence Phenotype, Floral Heteromorphisms, and Pollen Viability}

To determine the inflorescence morphotypes (scapes' morphology) of hybrids and apomicts, and if these corresponded to morphotypes similar to their parental plants (i.e., L. ovalifolium, L. nydeggeri, L. binervosum, L. dodartii) or new morphotypes, offspring plants were visually inspected during the flowering season (May-July 2019).

A total of three fresh flowers per plant was used for floral heteromorphism determinations, following [4,7]. Pollen and stigmas were dissected and covered with a drop of water and preparations were observed by light microscopy (Leitz HM-LUX 3), LEICA, Portugal), with $\times 400$ magnification. Plants were classified as having either A, B, C, or D pollen-stigma combinations (Figure 1, [7]).

For pollen viability estimations, from each cross, the pollen viability was counted considering all plants of a particular crossing (Figure S1). Fresh anthers from mature flowers at anthesis were collected, squashed, and the pollen spread onto the microscope slide. The grains were stained using Alexander's stain [43] under a coverslip and observed under light microscopy (Leitz HM-LUX 3). Total pollen viability estimates were performed by one person using three flowers per plant and counted with a $40 \times$ objective.

\subsection{Open Pollination Experiment and Floral Visitors}

Parental plants as well as each hybrid and apomictic plants originated from the above controlled crosses (Figure 1) were subjected to an open cross-pollination experiment and allowed to be visited by insects in the semi-closed greenhouse. Censuses were taken of 
insect visitors that regularly visited plants. Around 270 flowering stems were observed for 20 counts of $1 \mathrm{~h}$, making a total of $20 \mathrm{~h}$ of observations from May to July 2019. Observations were carried out between 10:00 $\mathrm{h}$ and 19:00 $\mathrm{h}$, during the period when insect adult flight abundance is greatest. Only the visitors touching reproductive parts of the flower were included in this study, which were then collected and taken to the laboratory for identification of insects' species and type of pollen grains carried in their body. Only the most abundantly collected specimens were identified at genus and species level, namely, Lepidoptera and Hymenoptera, as in $[44,45]$. Pollen grains (A or B types) transported by the different visitors were photographed using the camera ProgRes CT5 (Jenoptik Optical Systems, Jena, Germany) combined with the stereoscopic microscope stereoscopic microscope Mei-jiTechno model PKL-1Stand (Japan) $(70 \times)$.

\subsection{Seed Germination and Seedlings' Phenotype Evaluation}

Nine weeks after the open pollination experiment the seeds from hybrid and apomict plants, above mentioned, were harvested. Seeds were placed in Petri dishes with watersoaked filter paper in a growth chamber (Rumed), with controlled light and temperature conditions, at $18 \mathrm{~h}$ light $/ 6 \mathrm{~h}$ dark, at $25^{\circ} \mathrm{C}$ [12]. After two months, the seedlings were transferred to planting pots with commercial substrate (Siro) and kept in the semi-closed greenhouse. Each seedling was visually inspected to determine its phenotype, whether it fit the appearance of parental plants or if it presented a new morphology.

\subsection{Genome Size and DNA Ploidy Estimations in Seedlings}

The progeny of the open pollination experiment with atypical cotyledon number ( $>2$; pleiocotyly) and polyembryonic ( $>1$ embryo in one seed) seedlings were evaluated individually by flow cytometry to verify if their ploidy levels differed from their parental plants. Nuclei were isolated following the procedure of Galbraith et al., 1983 [46], in which $0.5 \mathrm{~cm}^{2}$ of fresh leaf tissue of each sample was chopped with a razor blade, simultaneously with $0.5 \mathrm{~cm}^{2}$ of fresh leaf tissue of the internal reference standard, in a Petri dish containing $1 \mathrm{~mL}$ of Woody Plant Buffer (WPB) [47]. As internal standard, Pisum sativum 'Ctirad' $(2 \mathrm{C}=9.0 \mathrm{pg})$ or Secale cereale 'Dankovske' $(2 \mathrm{C}=16.19 \mathrm{pg})$ [48] was utilized. The suspension was filtered through a $50-\mu \mathrm{m}$ mesh nylon filter, and propidium iodide $(50 \mu \mathrm{g} / \mathrm{mL})$ was added to stain the DNA. To avoid staining of double-stranded RNA, $50 \mu \mathrm{g} . \mathrm{mL}-1$ of RNAse (Fluka, Buchs, Switzerland) were also added to the suspension. After a 5-min incubation period, the samples were analyzed in a Partec CyFlow Space flow cytometer (Partec $\mathrm{GmbH}$, Görlitz, Germany) equipped with a green, solid-state laser (Cobolt Samba $532 \mathrm{~nm}$, operating at $30 \mathrm{~mW}$; Cobolt, Stockholm, Sweden), used to measure the relative fluorescence of stained nuclei. Results were obtained using PARTEC FLOMAX software (v. 2.9) (Sysmex Partec GmbH, Görlitz, Germany). About 5000-5500 nuclei per sample were examined.

The DNA-ploidy level was inferred as a relative position of the sample G1 peak to that of the internal standard. The value of genome size in mass units (2C in pg; sensu [49]) was obtained for each individual analyzed, using the following equation: Limonium $2 \mathrm{C}$ nuclear DNA content $(\mathrm{pg})=\left(\right.$ Limonium $\mathrm{G}_{1}$ peak mean/reference standard $\mathrm{G}_{1}$ peak mean ${ }^{*}$ genome size of the reference standard.

\subsection{Statistical Analyses}

Three binomial response variables were studied: (1) the pollen-stigma combination data, which were defined as the number of plants that presented pollen-stigma combination A (successes) out of the total number of plants analyzed; (2) the colpi number of pollen grains, which was defined as the number of grains with 3 colpi (successes) out of the total number of pollen grains analyzed; and (3) cotyledons' number data, which were defined as the number of seedlings with two cotyledons (successes) out of the total number of seedlings. In all cases, a generalized, linear, mixed model with a logit link function was fitted, considering one fixed effects' factor "reproductive modes", with two levels (sexual and apomixis), considering all crosses (five from sexual reproduction and four from 
apomixis reproduction). A likelihood ratio test, to compare reduced and full model, was conducted to test the effects of the mode of reproduction in the response variable studied. Data analysis was performed in $\mathrm{R}$ studio version 1.2.1335 software using the glm function.

Supplementary Materials: The following are available online at https:/ / www.mdpi.com/2223-7 747/10/1/169/s1. Figure S1: Pollen viability observed in parental plants and progeny obtained in homoploid (diploid $\times$ diploid) and heteroploid (tetraploid $\times$ diploid) controlled crosses. Figure S2: Genome size estimations of seedlings from open cross-pollination experiment of plants originated in homoploid (diploid $\times$ diploid) and heteroploid (tetraploid $\times$ diploid) crosses.

Author Contributions: A.D.C. conceived and coordinated the study. A.D.C. realized the reproductive studies. S.I.R.C. did plant maintenance and realized flow cytometric analyses. J.F. performed seedling morphotype analyses, observed insects' visits, did their capture, and drew the graphical abstract. E.B.d.S. supervised pollinators' experiments and did the identification of insects. A.D.C. and S.I.R.C. drafted the manuscript with the input of the co-authors. All authors have read and agreed to the published version of the manuscript.

Funding: The Open Access was funded by LEAF Project UID/AGR/04129/2020 and CEF Project UIDB $/ 00239 / 2020$.

Institutional Review Board Statement: Not applicable.

Informed Consent Statement: Not applicable.

Data Availability Statement: Not applicable.

Acknowledgments: This research was funded by by project PTDC/AGRPRO/4285/2014 and grant PTDC/ AGRPRO/4285/BM/2014 attributed to S.I.R.C. funded by Fundação para a Ciência e a Tecnologia I.P. (FCT), Portugal, and by the Forest Research Centre, a research unit funded by FCT, Portugal (UIDB/00239/2020).

Conflicts of Interest: The authors declare no conflict of interest.

\section{References}

1. Baker, H.G. The Evolution, functioning and breakdown of heteromorphic incompatibility systems. I. The Plumbaginaceae. Evolution 1966, 20, 349-368. [CrossRef]

2. Erben, M. Die Gattung Limonium im südwestmediterranen Raum. Mitt. Bot. Staatssamml. Miinchen 1978, 14, 361-631.

3. Costa, J.; Castro, S.; Loureiro, J.; Barrett, S.C. Experimental insights on the function of ancillary pollen and stigma polymorphisms in plants with heteromorphic incompatibility. Evolution 2017, 71, 121-134. [CrossRef] [PubMed]

4. Conceição, S.I.R.; Róis, A.S.; Caperta, A.D. Limonium homoploid and heteroploid intra-and interspecific crosses unveil seed anomalies and neopolyploidy related to sexual and/or apomictic reproduction. Taxon 2018, 67, 1153-1162. [CrossRef]

5. Dulberger, R. Intermorph structural differences between stigmatic papillae and pollen grains in relation to incompatibility in Plumbaginaceae. Proc. R. Soc. Lond. B 1975, 188, 257-274. [CrossRef]

6. Dulberger, R. S-gene action and the significance of characters in the heterostylous syndrome. Heredity 1975, 35, 407-415. [CrossRef]

7. Róis, A.S.; Sádio, F.; Paulo, O.S.; Teixeira, G.; Paes, A.P.; Espírito-Santo, D.; Sharbel, T.F.; Caperta, A.D. Phylogeography and modes of reproduction in diploid and tetraploid halophytes of Limonium species (Plumbaginaceae): Evidence for a pattern of geographical parthenogenesis. Ann. Bot. 2016, 117, 37-50. [CrossRef]

8. Costa, J.; Torices, R.; Barrett, S.C. Evolutionary history of the buildup and breakdown of the heterostylous syndrome in Plumbaginaceae. New Phytol. 2019, 224, 1278-1289. [CrossRef]

9. Baker, H.G. Dimorphism and monomorphism in the Plumbaginaceae. II. Pollen and stigmata in the genus Limonium. Ann. Bot. 1953, 17, 433-445. [CrossRef]

10. Baker, H.G. Corolla size in gynodioecious and gynomonoecious species of flowering plants. Proc. Leeds Phil. Soc. 1948, 5, 136-139.

11. Cortinhas, A.; Erben, M.; Paes, A.P.; Santo, D.E.; Guara-Requena, M.; Caperta, A.D. Taxonomic complexity in the halophyte Limonium vulgare and related taxa (Plumbaginaceae): Insights from analysis of morphological, reproductive and karyological data. Ann. Bot. 2015, 115, 369-383. [CrossRef]

12. Róis, A.S.; Teixeira, G.; Sharbel, T.F.; Fuchs, J.; Martins, S.; Espírito-Santo, D.; Caperta, A.D. Male fertility versus sterility, cytotype, and DNA quantitative variation in seed production in diploid and tetraploid sea lavenders (Limonium sp., Plumbaginaceae) reveal diversity in reproduction modes. Sex. Plant. Reprod. 2012, 25, 305-318. [CrossRef]

13. Erben, M. Karyotype differentiation and its consequences in Mediterranean Limonium. Webbia 1979, 34, 409-417. [CrossRef]

14. Boorman, L.A. Limonium vulgare Miller and L. humile Miller, in the biological flora of the British Isles. J. Ecol. 1967, 55, 221-232. [CrossRef] 
15. Khan, Z.; Santpere, G.; Traveset, A. Breeding system and ecological traits of the critically endangered endemic plant Limonium barceloi (Gil and Llorens) (Plumbaginaceae). Plant. Syst. Evol. 2012, 298, 1101-1110. [CrossRef]

16. Koch, M.A.; Dobeš, C.; Mitchell-Olds, T. Multiple hybrid formation in natural populations: Concerted evolution of the internal transcribed spacer of nuclear ribosomal DNA (ITS) in North American Arabis divaricarpa (Brassicaceae). Mol. Bio. Evol. 2003, 20, 338-350. [CrossRef]

17. Schranz, M.E.; Dobeš, C.; Koch, M.A.; Mitchell-Olds, T. Sexual reproduction, hybridization, apomixis, and polyploidization in the genus Boechera (Brassicaceae). Amer. J. Bot. 2005, 92, 1797-1810. [CrossRef]

18. Paun, O.; Greilhuber, J.; Temsch, E.M.; Hörandl, E. Patterns, sources and ecological implications of clonal diversity in apomictic Ranunculus carpaticola (Ranunculus auricomus complex, Ranunculaceae). Molec. Ecol. 2006, 15, 897-910. [CrossRef]

19. Kantama, L.; Sharbel, T.F.; Schranz, M.E.; Mitchell-Olds, T.; De Vries, S.; De Jong, H. Diploid apomicts of the Boechera holboellii complex display large-scale chromosome substitutions and aberrant chromosomes. Proc. Natl. Acad. Sci. USA 2007, 104, 14026-14031. [CrossRef]

20. Hodač, L.; Scheben, A.P.; Hojsgaard, D.; Paun, O.; Hörandl, E. ITS polymorphisms shed light on hybrid evolution in apomictic plants: A case study on the Ranunculus auricomus complex. PLoS ONE 2014, 9, e103003. [CrossRef]

21. Dahlgren, K.V.O. Zytologische und embryologische Studien über die Reihen Primulales und Plumbaginales. Kungl. Sven. Vetensk. Handl. 1916, 56, 1-80.

22. D'Amato, F. Triploidia e apomissia in Statice oleaefolia Scop. var. Confusa Godr. Caryologia 1949, 2, 71-84. [CrossRef]

23. Hjelmqvist, H.; Grazi, F. Studies on variation in embryo sac development. Bot. Not. 1964, 117, 141-166.

24. Caperta, A.D.; Castro, S.; Loureiro, J.; Róis, A.S.; Conceição, S.; Costa, J.; Rhazi, L.; Espírito Santo, D.; Arsénio, P. Biogeographical, ecological and ploidy variation in related asexual and sexual Limonium taxa (Plumbaginaceae). Bot. J. Linn. Soc. 2017, 183, 75-93. [CrossRef]

25. Caperta, A.D.; Conceição, S.I.R.; Róis, A.S.; Loureiro, J.; Castro, S. Cytogenetic features of sexual and asexual Limonium taxa (Plumbaginaceae). Taxon 2018, 67, 1143-1152. [CrossRef]

26. Flora Ibérica. Available online: http:/ / www.floraiberica.es/floraiberica/texto/pdfs /03_055_04_Limonium.pdf (accessed on 12 February 2020).

27. Erben, M. Limonium nydeggeri eine neue Art aus Sudwestportugal. Sendtnera 1999, 6, 103-107.

28. Stace, C. New Flora of the British Isles, 3rd ed.; Cambridge University Press: Cambridge, UK, 2010; pp. $243-248$.

29. Róis, A.S.; López, C.M.R.; Cortinhas, A.L.; Erben, M.; Espírito-Santo, D.; Wilkinson, M.J.; Caperta, A.D. Epigenetic rather than genetic factors may explain phenotypic divergence between coastal populations of diploid and tetraploid Limonium spp. (Plumbaginaceae) in Portugal. BMC Plant. Biol. 2013, 13, 205. [CrossRef]

30. Dobeš, C.; Scheffknecht, S.; Fenko, Y.; Prohaska, D.; Sykora, C.; Hülber, K. Asymmetric reproductive interference: The consequences of cross-pollination on reproductive success in sexual-apomictic populations of Potentilla puberula (Rosaceae). Ecol. Evol. 2018, 8, 365-381. [CrossRef]

31. Dobeš, C.; Milosevic, A.; Prohaska, D.; Scheffknecht, S.; Sharbel, T.F.; Hülber, K. Reproductive differentiation into sexual and apomictic polyploid cytotypes in Potentilla puberula (Potentilleae, Rosaceae). Ann. Bot. 2013, 112, 1159-1168. [CrossRef]

32. Hörandl, E. Evolutionary implications of self-compatibility and reproductive fitness in the apomictic Ranunculus auricomus polyploid complex (Ranunculaceae). Int. J. Plant. Sci. 2008, 169, 1219-1228. [CrossRef]

33. Mráz, P. Mentor effects in the genus Hieracium s. str. (Compositae, Lactuceae). Folia Geob. 2003, 38, 345-350.

34. Conceição, S.I.R.; Róis, A.S.; Caperta, A.D. Nonreduction via meiotic restitution and pollen heterogeneity may explain residual male fertility in triploid marine halophyte Limonium algarvense (Plumbaginaceae). Caryologia 2019, 72, 53-62. [CrossRef]

35. Maia, F.R.; Varassin, I.G.; Goldenberg, R. Apomixis does not affect visitation to flowers of Melastomataceae, but pollen sterility does. Plant. Biol. 2016, 18, 132-138. [CrossRef]

36. Natural History Museum. Available online: http:/ / www.nhm.ac.uk/hosts (accessed on 25 June 2020).

37. Zhang, A.Q.; He, S.; Zhai, Y.X.; Huang, S.Q. Does persistence of showy calyces in Limonium leptolobum enhance pollinator attraction? J. Plant. Ecol. 2015, 8, 182-186. [CrossRef]

38. Nowicke, J.W.; Skvarla, J.J. Pollen morphology and the relationship of the Plumbaginaceae, Polygonaceae, and Primulaceae to the order Centrospermae. Smithson. Contrib. Bot. 1976, 37, 1-64. [CrossRef]

39. Corley, M.F.V.; Ferreira, S.; Grundy, D.; Nunes, J.; Pires, P.; Rosete, J. New and interesting Portuguese Lepidoptera records from 2017 (Insecta: Lepidoptera). SHILAP Rev. Lepidopterol. 2018, 46, 551-576.

40. Clifton, J. Clepsis coriacana (Rebel, 1894) new to Europe plus further records of Clepsis peritana (Clemens, 1860) from Gibraltar (Lepidoptera: Tortricidae). SHILAP Rev. Lepidopterol. 2007, 35, 47-48.

41. Wvan, C. Syncotyly, pseudomonotyly, schizocotyly and pleicotyly within some dicotyledons. Biol. Jarl. Dodonaea 1981, 49, 166-183.

42. Carman, J.G. Asynchronous expression of duplicate genes in angiosperms may cause apomixis, bispory, tetraspory, and polyembryony. Biol. J. Linn. Soc. 1997, 61, 51-94. [CrossRef]

43. Alexander, M.P. Differential staining of aborted and non-aborted pollen. Stain Tech. 1969, 44, 117-122. [CrossRef]

44. Collingwood, C.; Prince, A. A guide to ants of Continental Portugal (Hymenoptera, Formicidae). Bol. Soc. Port. Entomol. 1998, 5, 49.

45. On-line Systematic Catalog of Plant Bugs (Insecta: Heteroptera: Miridae). Available online: http://research.amnh.org/pbi/ catalog/ (accessed on 25 June 2020). 
46. Galbraith, D.W.; Harkins, K.R.; Maddox, J.M.; Ayres, N.M.; Sharma, D.P.; Firoozabady, E. Rapid flow cytometric analysis of the cell cycle in intact plant tissues. Science 1983, 220, 1049-1051. [CrossRef]

47. Loureiro, J.; Rodriguez, E.; Doležel, J.; Santos, C. Two new nuclear isolation buffers for plant DNA flow cytometry: A test with 37 species. Ann. Bot. 2007, 100, 875-888. [CrossRef]

48. Doležel, J.; Greilhuber, J.; Lucretti, S.; Meister, A.; Lysák, M.A.; Nardi, L.; Obermayer, R. Plant genome size estimation by flow cytometry: Inter-laboratory comparison. Ann. Bot. 1998, 82, 17-26. [CrossRef]

49. Greilhuber, J.; Doležel, J.; Lysak, M.A.; Bennett, M.D. The origin, evolution and proposed stabilization of the terms 'genome size' and 'C-value' to describe nuclear DNA contents. Ann. Bot. 2005, 95, 255-260. [CrossRef] 